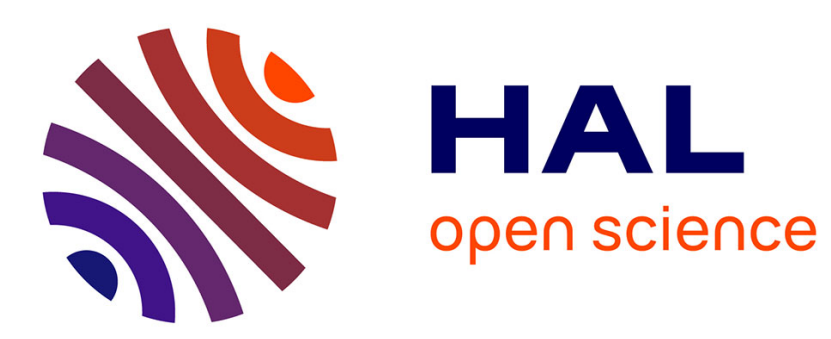

\title{
Densification of amorphous silicon prepared by hydrogen-ion-beam-assisted evaporation
}

\author{
H. Rinnert, M. Vergnat, G. Marchal, A. Burneau
}

\section{To cite this version:}

H. Rinnert, M. Vergnat, G. Marchal, A. Burneau. Densification of amorphous silicon prepared by hydrogen-ion-beam-assisted evaporation. Applied Physics Letters, 1996, 69 (11), pp.1582-1584. 10.1063/1.117037 . hal-02113429

\section{HAL Id: hal-02113429 \\ https://hal.science/hal-02113429}

Submitted on 28 Apr 2019

HAL is a multi-disciplinary open access archive for the deposit and dissemination of scientific research documents, whether they are published or not. The documents may come from teaching and research institutions in France or abroad, or from public or private research centers.
L'archive ouverte pluridisciplinaire HAL, est destinée au dépôt et à la diffusion de documents scientifiques de niveau recherche, publiés ou non, émanant des établissements d'enseignement et de recherche français ou étrangers, des laboratoires publics ou privés. 


\title{
Densification of amorphous silicon prepared by hydrogen-ion-beam- assisted evaporation
}

\author{
H. Rinnert, M. Vergnat, ${ }^{\text {a) }}$ and G. Marchal \\ Laboratoire de Métallurgie Physique et Science des Matériaux, (U.R.A. au C.N.R.S. No. 155), Université \\ Henri Poincaré Nancy 1, B. P. 239, 54506 Vandæuvre-lès-Nancy Cedex, France
}

\author{
A. Burneau \\ Laboratoire de Chimie Physique pour l'Environnement, (U.M.R. au C.N.R.S. No. 9992), Université Henri \\ Poincaré Nancy 1, 405, rue de Vandæuvre, 54600 Villers-lès-Nancy Cedex, France
}

(Received 4 March 1996; accepted for publication 1 July 1996)

\begin{abstract}
Hydrogenated amorphous silicon films were deposited by ion-beam-assisted evaporation onto substrates maintained at $120^{\circ} \mathrm{C}$. The influence of the substrate bias was studied. By combined infrared spectrometry and thermal desorption spectrometry experiments, it is inferred that the bombardment of the growing $a-\mathrm{Si}: \mathrm{H}$ film by energetic hydrogen ions produces a densification of the material without modification of the Si:H bonding. (C) 1996 American Institute of Physics. [S0003-6951(96)01737-8]
\end{abstract}

It is well known that, by passivating the dangling bonds of silicon, hydrogen reduces the density of electronic states in the gap of amorphous silicon and renders the material suitable to electronic applications. Except the elaboration methods based on glow-discharge cracking of silane and sputtering in an $\mathrm{Ar}-\mathrm{H}_{2}$ atmosphere, several attempts have been made to introduce hydrogen into evaporated $a$-Si films. Since molecular hydrogen is relatively stable, appreciable $\mathrm{Si}-\mathrm{H}$ bonding required the production of atomic hydrogen by dissociation of molecules in a heated tungsten tube ${ }^{1}$ or the use of an ion beam from a Kaufman-type source. ${ }^{2,3}$ With ion-beam-assisted evaporation, ion bombardment is essentially independent of silicon deposition and both can be more easily controlled. Decoupling these processes can also bring useful information for the understanding of the $a$-Si:H deposition mechanisms.

The purpose of this study is to describe the growth of $a-\mathrm{Si}: \mathrm{H}$ thin films using the electron cyclotron resonance (ECR) microwave plasma assisted evaporation method. The ECR microwave plasma sources are well known to provide high ion densities at low energies $(10-25 \mathrm{eV})$. The pressures $\left(>10^{-5}\right.$ Torr) required for stable operation of the source are compatible with the use of an electron beam gun. The reactive gas was pure hydrogen. The energy of the ions was varied by biasing the substrate. This letter shows that the accelerated hydrogen ions modify the microstructure of amorphous silicon. The films have been characterized by infrared spectrometry and thermal desorption spectrometry experiments.

The plasma generation chamber and the growth chamber were evacuated by a cryogenerator with a pumping rate of 1000 1/s. The background pressure was $10^{-8}$ Torr. Silicon was evaporated from an electron beam gun. The deposition rate $(1 \stackrel{\AA}{\mathrm{A}} / \mathrm{s})$ was monitored and controlled by a quartz microbalance system. The samples were deposited on (111) $\mathrm{Si}$ substrates. Their thickness was $2400 \AA$ A. The hydrogen flow in the ion source was regulated by maintaining the total pressure $P_{\mathrm{H}_{2}}$ in the evaporation chamber at $4 \times 10^{-5}$ Torr. The

${ }^{\text {a)} E l e c t r o n i c ~ m a i l: ~ v e r g n a t @ 1 p s . u-n a n c y . f r ~}$
$2.45 \mathrm{GHz}$ microwave energy of the ECR source was $200 \mathrm{~W}$. A $875 \mathrm{G}$ axial magnetic field was used to create electron cyclotron resonance and to promote efficient coupling of the microwaves to the plasma. The distance between the source and the substrate was $15 \mathrm{~cm}$. The substrate temperature was regulated and maintained at $120^{\circ} \mathrm{C}$.

Samples were prepared with different substrate voltages equal to $0,-200$, and $-300 \mathrm{~V}$. The hydrogen bonding configurations were obtained from Fourier transform infrared transmission measurements. Infrared spectra were recorded using a Perkin Elmer 2000 spectrometer with a resolution of $4 \mathrm{~cm}^{-1}$. The contribution of an uncoated reference silicon substrate was subtracted from the experimental spectra. The type of hydrogen bonding was also studied by thermal desorption spectrometry experiments. The films were inserted into a quartz tube evacuated by an ionic pump and were heated at a constant rate of $10{ }^{\circ} \mathrm{C} / \mathrm{min}$ to $800{ }^{\circ} \mathrm{C}$. The base pressure of the chamber was $2 \times 10^{-8}$ Torr. The gaseous components desorbing from the sample surface were detected by a quadrupole mass analyzer.

Infrared spectrometry spectra of samples prepared with substrate voltages equal to $0,-200$, and $-300 \mathrm{~V}$ are represented in Fig. 1 for the $1850-2300 \mathrm{~cm}^{-1}$ range and in Fig. 2 for the 500-1300 $\mathrm{cm}^{-1}$ range. For silicon prepared without bias, the $\mathrm{Si}-\mathrm{H}$ stretching vibration modes are dominated by the band at $2090 \mathrm{~cm}^{-1}$, which could be attributed to polyhydride groups $\mathrm{SiH}_{2},\left(\mathrm{SiH}_{2}\right)_{n}$, and $\mathrm{SiH}_{3}$ or to monohydride groups $\mathrm{SiH}$ located at internal surfaces or microvoids. A shoulder is clearly visible on the low-wave-number side: this band at $2000 \mathrm{~cm}^{-1}$ is associated to isolated $\mathrm{SiH}$ groups. Moreover, small bands appear at 2180 and $2240 \mathrm{~cm}^{-1}$, which can be attributed to $\mathrm{SiH}$ or $\mathrm{SiH}_{2}$ configurations containing oxygen atoms in their back bonds. For the same sample, two bands at 850 and $890 \mathrm{~cm}^{-1}$ are well visible. They correspond to the bending bands of polyhydride configurations and then confirm the important proportion of $\left(\mathrm{SiH}_{2}\right)_{n}$ or $\mathrm{SiH}_{3}$ groups. Moreover, absorption bands at 1050 and $980 \mathrm{~cm}^{-1}$ indicate oxygen contamination, which appears when the samples are exposed to ambient air. The absorption band near $640 \mathrm{~cm}^{-1}$ is assigned to the wagging band of 


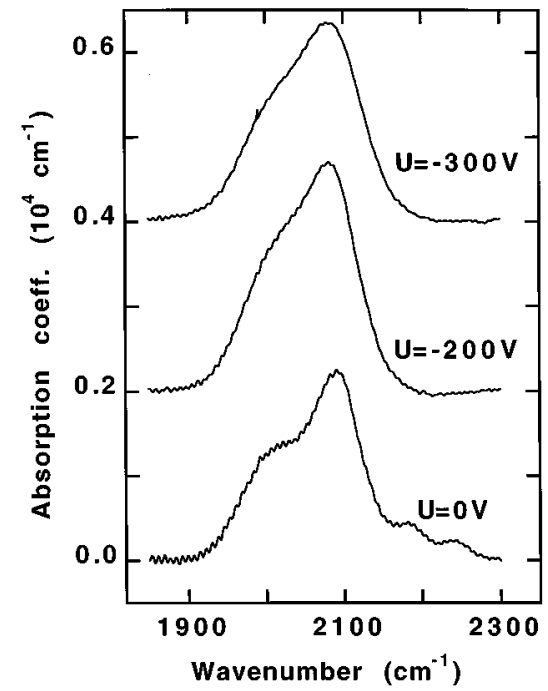

FIG. 1. Infrared absorption spectra in the range $1850-2300 \mathrm{~cm}^{-1}$ of $a$-Si:H samples prepared with different hydrogen-ion energies. The indicated voltages $U$ correspond to the substrate bias.

$\mathrm{SiH}_{n}(n=1,2,3)$. The bonded hydrogen content $C_{\mathrm{H}}$ was estimated from the integrated intensity of this band. With the usual proportionality constant $1.6 \times 10^{19} \mathrm{~cm}^{-2}, 4$ and an atomic density of silicon fixed to $5 \times 10^{22} \mathrm{~cm}^{-3}, C_{\mathrm{H}}$ was estimated to be equal to $21 \%$.

When the substrate is biased, the stretching vibration band is not modified. The oxygen-related bands have disappeared, but the proportion between the two peaks at 2000 and $2100 \mathrm{~cm}^{-1}$ remains unchanged. In the $500-1300 \mathrm{~cm}^{-1}$ range, the most striking difference is due to the disappearance of the oxidation peaks at 980 and $1050 \mathrm{~cm}^{-1}$. The two bands at 850 and $890 \mathrm{~cm}^{-1}$ are always visible. They correspond to polyhydride bonds and are correlated to the 2100 $\mathrm{cm}^{-1}$ peak that remains in the stretching vibration band. The bias does not influence the hydrogen bonding. The hydrogen content deduced from the $640 \mathrm{~cm}^{-1}$ peak is equal to $27 \%$ and $26 \%$ for $U=-200 \mathrm{~V}$ and $U=-300 \mathrm{~V}$, respectively.

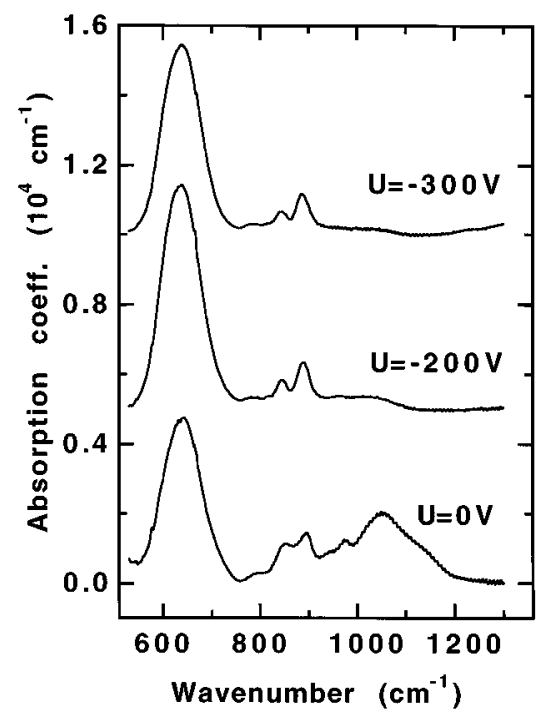

FIG. 2. Infrared absorption spectra in the range $500-1300 \mathrm{~cm}^{-1}$ of the samples described in Fig. 1.

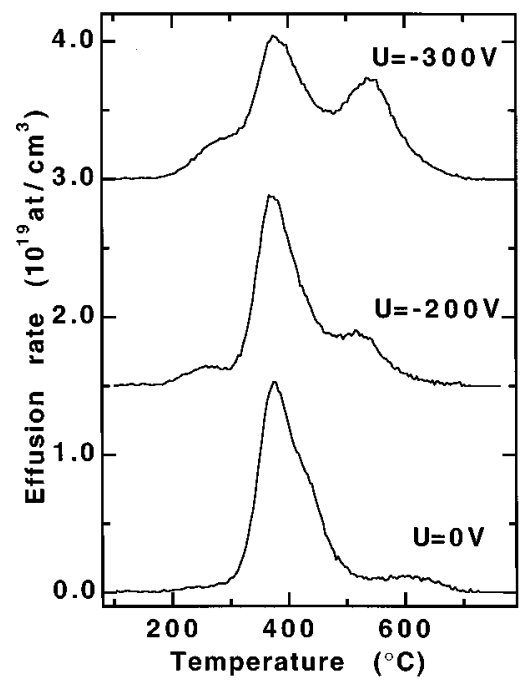

FIG. 3. Thermal effusion spectra of the $a$-Si:H samples described in Fig. 1.

Therefore, the evolution of the infrared spectra with the substrate bias is very different from that obtained with the substrate temperature since the hydrogen content decreases and the ratio of the bonds numbers $\mathrm{SiH} / \mathrm{SiH}_{2}$ increases with increasing temperatures.

The hydrogen effusion spectra of the three samples are represented in Fig. 3. The spectrum of the sample prepared without bias shows a peak around $400{ }^{\circ} \mathrm{C}$. It strongly differs from the spectra obtained with glow-discharged silicon that present a desorption peak at $400{ }^{\circ} \mathrm{C}$ and a diffusion peak at $600{ }^{\circ} \mathrm{C}$ or only the high-temperature peak. ${ }^{5}$ But it is very similar to the spectra obtained for hydrogenated silicon prepared by sputtering ${ }^{6}$ or by evaporation ${ }^{7}$ on substrates maintained at $77 \mathrm{~K}$. This peak is usually associated with desorption from internal surfaces in a void-rich material. In fact, there is also a slight shoulder on the high-temperature side. The principal peak corresponds to the $\mathrm{SiH}_{2}$ units that are the dominant configurations, as shown by infrared spectrometry. The shoulder corresponds to the isolated $\mathrm{SiH}$ configurations. For $U=-200 \mathrm{~V}$ and $U=-300 \mathrm{~V}$, two other peaks appear at $260{ }^{\circ} \mathrm{C}$ and $550{ }^{\circ} \mathrm{C}$. Their intensity increases with bias. The origin of the low-temperature peak is undetermined. The high-temperature peak could correspond to a diffusion phenomenon. An easy way to verify this hypothesis is the measurement of the thickness dependence. If diffusion limits the evolution rate, the rising diffusion length with increasing film thickness will result in a shift of the evolution peak to higher temperatures. Such a shift is really observed since the temperature of this peak increases from $480{ }^{\circ} \mathrm{C}$ to $580{ }^{\circ} \mathrm{C}$ when the thickness increases from 500 to $5000 \AA$. The first peak at $400{ }^{\circ} \mathrm{C}$ does not shift. By biasing the substrate, it is then possible to change the microstructure of the film because it presents no more postoxidation and some hydrogen atoms must diffuse through the film before desorbing. This microstructure change most likely corresponds to a densification of the material. Such a conclusion was already given for sputtered films that present low-density regions. It is generally admitted for these samples that dense microstructure is more resistant to postdeposition oxidation. ${ }^{8}$

The diffusion peak of the hydrogen-effusion spectrum 
clearly appears for a voltage equal to $300 \mathrm{~V}$. In order to confirm this threshold value, deuterated samples were prepared with different substrate voltages. For $U=0 \mathrm{~V}$ and $U=-100 \mathrm{~V}$, the effusion spectra show only the desorption peak at $400{ }^{\circ} \mathrm{C}$. For $U=-200 \mathrm{~V}$, the effusion spectrum was comparable to that of the hydrogenated sample prepared with $U=-300 \mathrm{~V}$. The microstructure change of the material is, therefore, dependent on both the bias and the ion mass. The models describing the mechanisms of the surface reactions in the deposition process of $a-\mathrm{Si}: \mathrm{H}$ or $a-\mathrm{C}: \mathrm{H}$ films by glow discharge ${ }^{9,10}$ cannot be applied because their surface is bombarded by hydrogen atoms and by $\mathrm{SiH}_{3}$ or $\mathrm{CH}_{3}$ radicals formed in the plasma. In the case of evaporation, the sticking coefficient of the evaporated silicon atoms is supposed to be equal to unity and the incident particles are the hydrogen molecules, atoms, or ions. A very simple model consists in saying that some incident hydrogen particles bond to silicon. Some hydrogen ions can also transfer their energy to the silicon atoms, which will improve their surface diffusion and then the densification of the microstructure. By considering a direct elastic collision between an incident hydrogen (deuterium) ion of mass $m_{1}$ and of energy $E_{1}=e|U|$ and a motionless silicon atom of mass $m_{2}$, the energy of the silicon atom after the collision is $E_{2}=\left[4 m_{1} m_{2} /\left(m_{1}+m_{2}\right)^{2}\right] e|U|$. The value $E_{2}$ has approximately the same value for hydrogen atoms with $U=-300 \mathrm{~V}$ and deuterium atoms with $U=$ $-200 \mathrm{~V}$. This simple model explains the ballistic effect of the hydrogen ions and shows that the diffusion peak appears for an energy given to the silicon atoms approximately equal to $0.4 \mathrm{eV}$. This value could correspond to the activation energy of the surface diffusion of the silicon adatoms.

In summary, these ion-beam-assisted deposition experiments show that even bombardment by light ions accelerated with a moderate voltage can strongly modify the film structure. For hydrogenated amorphous silicon, hydrogen ions with $300 \mathrm{eV}$ energy change neither the hydrogen content nor the proportion of $\mathrm{SiH}_{2}$ and $\mathrm{SiH}$ bonds, but the postoxidation is suppressed and a high-temperature diffusion peak appears in the effusion spectrum. These characteristics are generally correlated to a densification of the microstructure.

${ }^{1}$ M. Vergnat, G. Marchal, and Ph. Mangin, J. Non-Cryst. Solids 137\&138, 907 (1991).

${ }^{2}$ V. Grasso, A. M. Mezzasalma, and F. Neri, Solid State Commun. 41, 675 (1982).

${ }^{3}$ M. Shindo, S. Sato, I. Myokan, S. Mano, and T. Shibata, J. Non-Cryst. Solids 59\&60, 747 (1983).

${ }^{4}$ H. R. Shanks, C. J. Fang, L. Ley, M. Cardona, F. J. Demond, and S. Kalbitzer, Phys. Status Solidi B 100, 43 (1980).

${ }^{5}$ W. Beyer, Physica B 170, 105 (1991).

${ }^{6}$ F. Kozlowski, V. Petrova-Koch, A. Kux, W. Stadler, A. Fleischmann, and H. Sigmund, J. Non-Cryst. Solids 137\&138, 91 (1991).

${ }^{7}$ M. Vergnat, N. Hadj Zoubir, S. Houssaini, and G. Marchal, Appl. Phys. Lett. 66, 1647 (1995).

${ }^{8}$ R. C. Ross and R. Messier, J. Appl. Phys. 52, 5329 (1981).

${ }^{9}$ K. Maeda, A. Kuroe, and I. Umezu, Phys. Rev. B 51, 10635 (1995).

${ }^{10}$ W. Möller, W. Fukarek, K. Lange, A. von Keudell, and W. Jacob, Jpn. J. Appl. Phys. 34, 2163 (1995). 